\title{
Ranibizumab in neovascular age-related macular degeneration: a 5-year follow-up
}

\author{
This article was published in the following Dove Press journal: \\ Clinical Ophthalmology \\ 8 June 2016 \\ Number of times this article has been viewed
}

\section{Nadezhda P Cvetkova \\ Kristina Hölldobler \\ Philipp Prahs \\ Viola Radeck \\ Horst Helbig \\ David Märker}

Department of Ophthalmology, University of Regensburg,

Regensburg, Germany
Correspondence: Nadezhda P Cvetkova Department of Ophthalmology, University of Regensburg, Franz-JosefStrauß-Allee II, 93053 Regensburg, Germany

Tel +4994I 944920 I

$\mathrm{Fax}+499419449202$

Email nadezhda.cvetkova@ukr.de
Purpose: Our aim was to evaluate an optical coherence tomography (OCT) and visual acuity (VA)-guided, variable-dosing regimen with intravitreal ranibizumab injection for treating patients with neovascular age-related macular degeneration (AMD) from 2007 to 2012.

Design: This was a retrospective clinical study of 5 years follow-up in a tertiary eye center. Patients and methods: In this study, 66 patients with neovascular AMD (mean age of 74 years, SD 8.7 years) were included. We investigated the development of best-corrected visual acuity (BCVA), the number of intravitreal injections, and the central retinal thickness measured with OCT (OCT Spectralis) over 5 years of intravitreal treatment.

Results: The mean number of intravitreal ranibizumab injections over 5 years was 8.8 . The mean BCVA before therapy was 0.4 logarithm of the minimum angle of resolution (logMAR). After 5 years of therapy, the mean BCVA was $0.6 \log M A R$. In all, 16\% of treated patients had stable VA over 5 years and $10 \%$ of study eyes approved their VA. The mean OCT-measured central retinal thickness at the beginning of this study was $295 \mu \mathrm{m}$; after 5 years of treatment, the mean central retinal thickness was $315 \mu \mathrm{m}$. There was an increase in central retinal thickness in $47.5 \%$ of examined eyes.

Conclusion: Other studies showed VA improvement in OCT-guided variable-dosing regimens. Our study revealed a moderate decrease in VA after a total mean injection number as low as 8.8 injections over 5 years. In OCT, an increase in central retinal thickness over 5 years could be observed. Probably, this is due to deficient treatment when comparing the total injection number to other treatment regimens. Anti-VEGF therapy helps to keep the VA stable for a period of time, but cannot totally stop the progression of the disease completely. Patients with late stages of neovascular AMD can maintain VA even if they are relatively undertreated.

Keywords: AMD, neovascular, OCT, ranibizumab, retina

\section{Introduction}

Neovascular age-related macular degeneration (AMD) is a chronic, progressive disease that causes irreversible loss of vision among elderly people in developed countries. ${ }^{1}$ Intravitreal anti-vascular endothelial growth factor (VEGF) therapy, the current standard for neovascular AMD, inhibits the progression of disease but does not seem to act on the causative mechanism underlying VEGF overexpression and the onset of active disease. It is unclear whether ocular anti-VEGF therapy leads to a cure and how many patients require long-term treatment for recurrent exudation.

Ocular anti-VEGF therapy has been widely used in clinical practice for many years. Ranibizumab (Lucentis; Genentech, Inc., South San Francisco, CA, USA) was approved in USA in June 2006. Even earlier than that, bevacizumab (Avastin; Genentech, Inc.) was described as an off-label ocular therapy. ${ }^{2}$ In Germany, three VEGF inhibitors were approved for the treatment of neovascular AMD: pegaptanib (Macugen; Pfizer, 
Inc., New York, NY, USA), ranibizumab (Lucentis; Novartis International AG, Basel, Switzerland), and recently aflibercept (Eylea; Bayer AG, Leverkusen, Germany).

The aim of this study was to evaluate the effect of ranibizumab on patients with neovascular AMD under real-life conditions. It was a retrospective clinical study of 5 years follow-up in a tertiary eye center. We evaluated an optical coherence tomography (OCT) and visual acuity (VA)-guided, variable-dosing regimen with intravitreal ranibizumab injection for treating patients with neovascular AMD from 2007 to 2012.

\section{Patients and methods Study design}

This was a retrospective clinical study of 5 years follow-up of a cohort of patients with neovascular AMD treated with ranibizumab in a tertiary eye center. The study was conducted in accordance with the tenets of the Declaration of Helsinki. The ethics committee of the University of Regensburg did not require that ethics approval and patient consent be sought and obtained for this study, due to its retrospective nature and because all data was de-identified.

\section{Patients}

In this study, 66 patients (39 females, 27 males) with neovascular AMD (mean 74 years; SD 8.7 years) were studied. Only patients with a follow-up as long as 5 years were included in this study; there were no other inclusion criteria. In 14 patients, both eyes were treated. Neovascular AMD was diagnosed according to the following ophthalmologic diagnostic procedures: retinal examination by means of funduscopy, fluorescein angiography, and OCT.

\section{Methods}

OCT (OCT Spectralis; Heidelberg Instruments, Heidelberg, Germany) quantitative assessments were obtained using six diagonal fast scans. The central retinal thickness was measured as the distance between internal limiting membrane (inner boundary) and the retinal pigment epithelium, and the Bruch membrane (outer boundary). We used images where these boundaries were appropriately identified by the algorithm. We investigated the development of the retinal thickness during the treatment.

The mean VA was calculated arithmetically and on a logarithmic basis (a difference of 0.1 logarithm of the minimum angle of resolution [logMAR] level is equivalent to one early treatment diabetic retinopathy study [EDTRS] line or five letters).
The change in best-corrected visual acuity (BCVA) and in retinal thickness was analyzed using descriptive statistics (mean and standard error of mean). The total number of injections received by a patient was registered. Data from mean VA and mean retinal thickness after each year of therapy were statistically compared using the paired Student's $t$-test. Statistical significance was defined as $P<0.05$.

\section{Results}

\section{Baseline characteristics}

Between 2007 and 2012, 66 patients (39 females, 27 males) with neovascular AMD were enrolled in this study. The mean age of these patients was 74 years (SD 8.7 years). All patients were Caucasians.

Our treatment regimen was based on European dosing recommendations with a loading phase of three injections. Retreatment was necessary in case of the following: visual loss of greater than five letters, a new hemorrhage, or a new lesion activity on fluorescence angiography. Additionally, an increase in retinal thickness of $>100 \mu \mathrm{m}$ measured by OCT was considered as an indication for retreatment. These therapeutic criteria were adopted from the prospective OCT study with Lucentis for neovascular AMD (PrONTO studies). PrONTO studies showed better results than the randomized double-masked, sham-controlled trial of ranibizumab for neovascular AMD (PIER study), which used a 3-month treatment regimen followed by ranibizumab injection every 3 months. ${ }^{3-5}$ In our study, the mean number of intravitreal injections over 5 years was 8.8. There was a decrease in the number of intravitreal injections between 2008 and 2009 with a mean number of two injections per year. From 2009 to 2012, there was an increase in the number of intravitreal injections, which resulted in a stabilization of VA (Figure 1).

\section{VA and OCT outcomes}

After the first year of therapy, a significant improvement in VA was detected $(P<0.01$; Figure 2$)$. This was associated

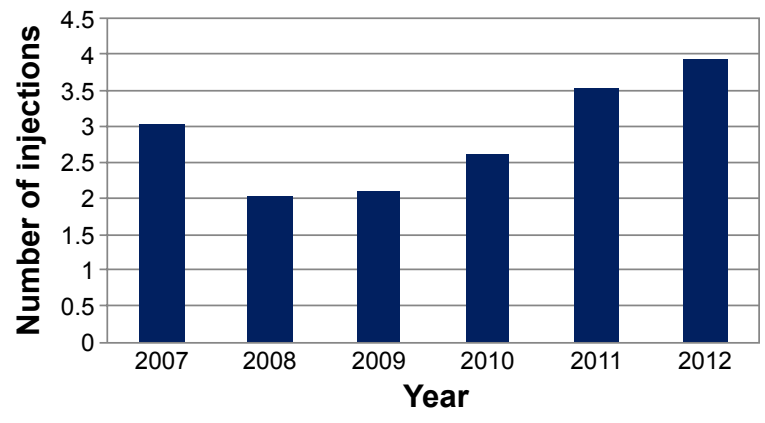

Figure I Increase in the number of injections per year from 2009 to 2012 . 


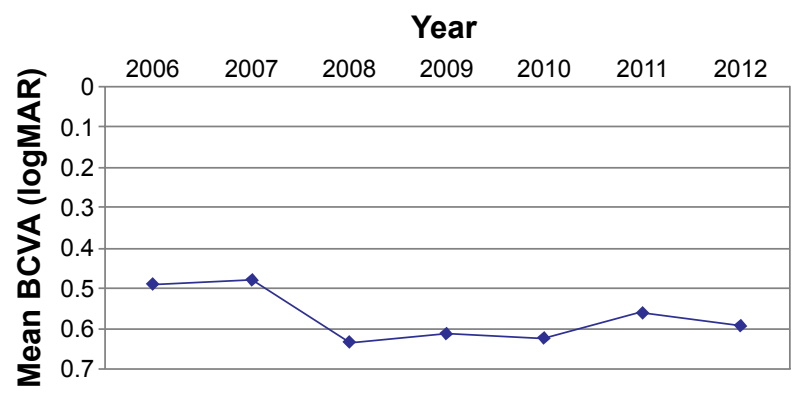

Figure 2 Development of BCVA during therapy.

Abbreviations: BCVA, best-corrected visual acuity; logMAR, logarithm of the minimum angle of resolution.

with a significant decrease in the central retinal thickness measured by OCT $(P<0.01$; Figure 3$)$. The mean central retinal thickness decreased by $37.8 \mu \mathrm{m}$, and the mean VA increased by $0.01 \log$ MAR. In the following 2 years, there was a decrease in the number of intravitreal injections (mean number of injections in 2008 was 2.03; mean number of injections in 2009 was 2.1), which resulted in a significant decrease in BCVA $(P<0.01)$ and an increase in central retinal thickness, which was not statistically significant $(P>0.01)$. There was a correlation between the increase in central retinal thickness and the decrease in BCVA.

In the following 2 years, the number of intravitreal injections increased, which resulted in a significant increase in VA $(P<0.01)$ and a corresponding decrease in central retinal thickness $(P>0.01$; Figures 2 and 3$)$.

Over 5 years of follow-up, 16 patients (20\%) had stable VA. In all, ten (12.5\%) patients had improved VA and 54 (67.5\%) had moderate VA loss. We detected a decrease in central retinal thickness in 37 (46.3\%) eyes, a slight increase in central retinal thickness in 38 (47.5\%) eyes, and there was no difference between the central retinal thickness measured by OCT in the beginning and in the end of this study in one $(1.3 \%)$ eye.

\section{Discussion}

The present retrospective study of 66 patients observed the treatment of neovascular AMD with ranibizumab

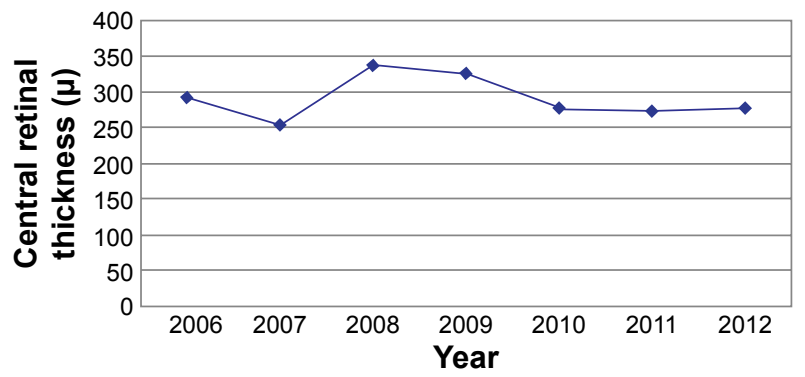

Figure 3 Development of central retinal thickness during therapy. under real-life conditions. The patients got a total mean of 8.8 injections during a period of 5 years. In previous randomized clinical trials, the number of intravitreal injections received by patients was higher. The mean number of ranibizumab injections during 2 years of treatment in the ranibizumab versus verteporfin photodynamic therapy for neovascular AMD study (ANCOR study) was 21.3. ${ }^{6}$ The patients in the CATT study (ranibizumab and bevacizumab for neovascular AMD) were treated with a mean of seven additional injections during the first year. ${ }^{7}$ The patients who finished the HORIZON study were treated in the SEVEN-UP study. In this study the patients got a mean number of 6.8 injections per year for a period of 3.4 years, with a total mean of 23.12 injections per person for this period. ${ }^{8}$

The striking differences in retreatment numbers show that therapy in a daily routine may differ significantly from that in controlled clinical trials. The COMPASS study (efficacy of treatment with ranibizumab in patients with wet AMD in routine clinical care), another multicentre prospective, non-interventional study, also showed an undertreatment of patients with neovascular AMD. Patients received a total mean of 4.5 injections: three injections during upload phase and 1.5 additional injections during the maintenance phase of 12 months. ${ }^{9}$ It also showed that under real-life conditions, a considerably lower number of patients received the number of injections required to improve or maintain VA during the maintenance phase using previously recommended retreatment criteria.

Probably, the criteria from the PrONTO study are too broad for an individual effective treatment of recurrence of neovascular AMD under a routine clinical setting. In uncontrolled, retrospective analyses, it was shown that a pro re nata (PRN) regimen with fewer than five injections in the first year was not able to achieve VA improvement. ${ }^{10,11}$ This treatment strategy was based on mathematical drug and disease model recommending 8.1 injections to be needed in the first year of treatment. ${ }^{12}$ Under routine clinical conditions, it seems that these retreatment criteria are not sufficient enough to detect recurrence and VA did not achieve the levels expected in other clinical trials. ${ }^{13}$ A systematic review of as needed versus treat and extend anti-VEGF treatment regimens compared eight studies meeting treat and extend protocol and 62 studies meeting PRN protocol. The treat and extend group received an average of 8.09 injections at the first year compared to the PRN group who received a mean of 5.6 injections. The mean improvement in VA in the treat and extend group was 10.4 ETDRS letters compared to 5.4 ETDRS letters in the PRN group. The study suggested superiority of the treat and 
extend treatment to PRN regimen in a 12 -month period. ${ }^{14}$ Randomized clinical trials should be done to evaluate longterm efficacy outcomes with these regimens.

One reason for the moderate decrease in VA in the present study might be the fact that decimal VA testing was used. This standard VA testing is probably not sensitive enough to detect recurrence sufficiently early. Most controlled clinical studies use ETDRS charts, which are more sensitive for the development of VA. The same reason for poor VA outcome is suggested in the COMPASS study, which used Snellen VA testing. ${ }^{9}$

Therefore, in our study, OCT data were included to assess the necessity of retreatment. OCT retreatment criteria were based on the recommendations of the German ophthalmological societies (German Ophthalmological Society, Association of Ophthalmologists, and Retina Society). They advise the implementation of morphologic criteria for reinjection (new hemorrhage or morphologic criteria on OCT). ${ }^{3}$

Despite these established retreatment criteria, our study showed a moderate decline in BCVA over 5 years. The possible reasons are the irregular visits of our patients and the poor response to treatment of some patients. Surprisingly, despite these restrictions, VA remained on a stable low level, which shows that also a low number of intravitreal injections can help to prevent greater visual loss and a stabilization of $\mathrm{VA}$ in AMD patients.

The authors of the COMPASS study consider that patients receiving up to seven injections of ranibizumab during a follow-up period of 15 months displayed the best visual outcomes, which is similar to the finding from the CATT study. ${ }^{7,9}$ Patients receiving more than five additional injections at 15 months did not improve in VA compared to those receiving four additional injections. In another study by Heimes et al, ${ }^{15}$ it was reported that flexible, VA-driven ranibizumab retreatment regimen, used in clinical practice in Germany, generally results in a decline in BCVA during the 12 months of follow-up.

The mean number of intravitreal injections during the first year of follow-up was as low as 3.03, which is significantly below the number of injections in other studies and clearly below the expected number of injections to maintain VA. There was an increase in the number of intravitreal injections up to 3.93 in the last 2 years of follow-up. The reason for the increase in injections in the last years of the study is probably the fact that during this period, ranibizumab treatment was established in Germany and both clinicians as well as patients gained more experience in treatment modalities. Notably, because of the increase in the number of intravitreal injections during the last years of observation, VA and central retinal thickness remained stable over this period.

\section{Conclusion}

Studies such as MARINA, ANCHOR, and CATT showed VA improvement in OCT-guided variable-dosing regimens with a high number of intravitreal injections. Our study revealed a moderate loss in VA and a slight increase in central retinal thickness during a 5-year follow-up of patients with neovascular AMD with a mean injection number as low as 8.8. The overall treatment success was below that shown in controlled clinical trials. These are results of a deficient treatment.

In particular, elderly patients were not able to travel long distances often for regular visits in our clinic. Furthermore, many patients suffered from later stages of AMD (initial BCVA 0.4 logMAR). It seems that under real-life conditions, recurrences and the need for retreatment are detected later than in controlled clinical trials.

Anti-VEGF therapy helps to stabilize VA and to prevent greater loss of vision, but cannot completely stop the progress of the disease.

\section{Acknowledgments}

This study was presented as a poster at ARVO 2014, Orlando, FL, USA.

\section{Disclosure}

The authors report no conflicts of interest in this work.

\section{References}

1. Jager RD, Mieler WF, Miller JW. Age-related macular degeneration. N Engl J Med. 2008;358(24):2606-2617.

2. Michels S, Rosenfeld PJ, Puliafito CA, Marcus EN, Venkatraman AS. Systemic Bevacizumab (Avastin) therapy for neovascular age-related macular degeneration twelve-week results of an uncontrolled open-label clinical study. Ophthalmology. 2005;112(6):1035-1047.

3. Stellungnahmeder Deutschen Ophthalmologischen Gesellschaft, der Retinologischen Gesellschaft unddes Berufsverbandes der Augenärzte Deutschlands. Die Anti-VEGF-Therapie bei der neovaskulären altersabhängigen Makuladegeneration. [Statement of the German Ophthalmological Society and the Association of Ophthalmologists about the anti- VEGF therapy in neovascular age related macular degeneration]. Therapeutische Strategien; 2013:1-25. German.

4. Abraham P, Yue H, Wilson L. Randomized, double-masked, sham-controlled trial of ranibizumab for neovascular age-related macular degeneration: PIER study year 2. Am J Ophthalmol. 2010;150(3):315. e1-324.e1.

5. Regillo CD, Brown DM, Abraham P, et al. Randomized, double-masked, sham-controlled trial of ranibizumab for neovascular age-related macular degeneration: PIER study year 1. Am J Ophthalmol. 2008;145(2): 239-248.

6. Brown DM, Michels M, Kaiser PK, et al. Ranibizumab versus verteporfin photodynamic therapy for neovascular age-related macular degeneration: two-year results of the ANCHOR study. Ophthalmology. 2009;116(1): 57.e5-65.e5. 
7. CATT Research Group, Martin DF, Maguire MG, et al. Ranibizumab and Bevacizumab for neovascular age-related macular degeneration. N Engl J Med. 2011;364(20):1897-1908.

8. Rofagha S, Bhisitkul RB, Boyer DS, Sadda SR, Zhang K; SEVEN-UP Study Group. Seven-year outcomes in ranibizumab treated patients in ANCHOR, MARINA, and HORIZON: a multicenter cohort study (SEVEN-UP). Ophthalmology. 2013;120(11):2292-2299.

9. Wolf A, Kampik A. Efficacy of treatment with Ranibizumab in patients with wet age-related macular degeneration in routine clinical care: data from the COMPASS health services research. Graefes Arch Clin Exp Ophthalmol. 2014;252(4):647-655.

10. Cohen SY, Dubois L, Tadayoni R, et al. Results of one-year's treatment with Ranibizumab for exudative age-related macular degeneration in a clinical setting. Am J Ophthalmol. 2009;148(3):409-413.

11. Dadgostar H, Ventura AA, Chung JY, Sharma S, Kaiser PK. Evaluation of injection frequency and visual acuity outcomes for Ranibizumab monotherapy in exudative age-related macular degeneration. Ophthalmology. 2009;116(9):1740-1747.
12. Holz FG, Korobelnik J-F, Lanzetta P, et al. The effects of a flexible visual acuity-driven Ranibizumab treatment regimen in age-related macular degeneration: outcomes of a drug and disease model. Invest Ophthalmol Vis Sci. 2010;51(1):405-412.

13. Wolf A, Reznicek L, Muhr J, Ulbig M, Kampik A, Haritoglou C. Treatment of recurrent neovascular age-related macular degeneration with Ranibizumab according to the PrONTO scheme. Ophthalmologe. 2013;110(8):740-745

14. Chin-Yee D, Eck T, Fowler S, Hardi A, Apte RS. A systematic review of as needed versus treat and extend ranibizumab or bevacizumab treatment regimens for neovascular age-related macular degeneration. Br J Ophthalmol. Epub 2015 Oct 29.

15. Heimes B, Lommatzsch A, Zeimer M, et al. Long-term visual course after anti-VEGF therapy for exudative AMD in clinical practice evaluation of the German reinjection scheme. Graefes Arch Clin Exp Ophthalmol. 2011;249(5):639-644.
Clinical Ophthalmology

\section{Publish your work in this journal}

Clinical Ophthalmology is an international, peer-reviewed journa covering all subspecialties within ophthalmology. Key topics include: Optometry; Visual science; Pharmacology and drug therapy in eye diseases; Basic Sciences; Primary and Secondary eye care; Patient Safety and Quality of Care Improvements. This journal is indexed on

Submit your manuscript here: http://www.dovepress.com/clinical-ophthalmology-journal

\section{Dovepress}

PubMed Central and CAS, and is the official journal of The Society of Clinical Ophthalmology (SCO). The manuscript management system is completely online and includes a very quick and fair peer-review system, which is all easy to use. Visit http://www.dovepress.com/ testimonials.php to read real quotes from published authors. 